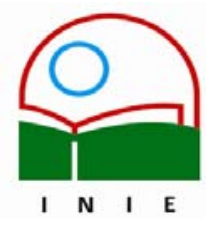

Universidad de Costa Rica

Facultad de Educación

Instituto de Investigación en Educación

ACTUALIDADES INVESTIGATIVAS EN EDUCACION

\title{
DOS PERSONAJES: UN PENSAMIENTO EDUCATIVO LATINOAMERICANO
}

Roxana Morales Bonilla ${ }^{1}$

Resumen: En este ensayo, se analiza el aporte que los pedagogos Paulo Freire e Ignacio Martín-Baró, brindaron a la educación latinoamericana. Su labor educativa plantea alternativas pedagógicas contestatarias que luchan contra la injusticia social, económica, política y cultural. Este enfoque propone metodologías participativas y liberadoras que ofrecen contenidos socialmente emancipadores. De tal forma esta nueva visión produce una reinterpretación y organización de los procesos pedagógicos vigentes.

\section{Palabras clave: PEDAGOGÍA LIBERADORA/ EDUCACIÓN DEMOCRÁTICA/ PEDAGOGÍA CRÍTICA/ EDUCACIÓN BANCARIA/}

\begin{abstract}
In this essay, the contribution brought by the pedagogues Paulo Freire and Ignacio Martín-Baró to Latin American education is analyzed. Their educative work presents pedagogical alternatives that run against the establishment; fighting against social, economical, political and cultural injustice. This approach proposes cooperative and liberating methodologies that offer socially-emancipating contents. In this manner, this new vision takes a new interpretation and organization of the present pedagogical processes.
\end{abstract}

Keywords: LIBERATING PEDAGOGYI DEMOCRATIC EDUCATION/ CRITICAL PEDAGOGYI BANKING EDUCATION/

\section{Introducción}

Entre 1974 y 1975, la Universidad de Costa Rica Ilamó a la población estudiantil universitaria interesada en participar en un proyecto de alfabetización para personas adultas en la provincia de Guanacaste, Costa Rica. Para ese momento, terminaba mi bachillerato en la carrera de Sociología y, en mis años de estudiante universitaria, el compromiso social, la búsqueda de la justicia y la teorización acerca de la lucha y la no explotación de las clases sociales, conformaban los ejes temáticos que recibía de mis profesores y profesoras de la carrera de Sociología.

\footnotetext{
${ }^{1}$ Magister Scientae en Educación con énfasis en educación de adultos; Licenciada en Socióloga ambos títulos de la Universidad de Costa Rica; Licenciada en Docencia de la Universidad Estatal a Distancia; diplomado en Redes, Multimedia y videoconferencia en CREFAL, México. Investigaciones en: Evaluación integral, del y la docente universitario; pedagogía universitaria; perfil del docente universitario para la educación básica, curriculum y género sensitivo, investigaciones en la UCR y en la UNA. Profesora universitaria por más de 15 años en las universidades públicas del país.
}

Correo electrónico: roxmo72@hotmail.com

Artículo presentado: 4 de octubre, 2004

Aprobado: 28 de marzo, 2005 
Cuando me informé de este llamado y como guanacasteca, vivencié ese compromiso social con mis coterráneos analfabetos y analfabetas y, como futura socióloga, asumí el reto de incorporarme al proyecto de alfabetización para personas adultas.

A esta petición, acudimos estudiantes de las carreras de: Medicina, Trabajo Social, Historia, Lenguas Modernas (Inglés y Filología), Psicología, Odontología, Filosofía, Educación, Sociología, Química y Teatro, entre otras.

Nos sentíamos los dueños y las dueñas del mundo, pues nos proponíamos transformarlo a través de la palabra.

En la Facultad de Educación de la Universidad de Costa Rica, nos dieron la información inicial, que era un proyecto educativo coordinado por la Vicerrectoría de Acción Social de la Universidad de Costa Rica, la Facultad de Educación, el Ministerio de Educación Pública y la Organización de Estados Americanos. Durante un mes nos capacitaron y sensibilizaron con el método pedagógico de alfabetización, que fue el método de Paulo Freire, y tuve la oportunidad de conocer, por primera vez, a Tito Quirós, Arnoldo Mora, José Luis Valenciano, Ana Cecilia Hernández, María Cecilia Vega, Marielos Giralt, María Suárez, Yolanda Rojas, y profesoras y profesores universitarios de renombre en las Ciencias de la Educación y de las Ciencias Sociales, y cercanos a los movimientos estudiantiles que en esa época tenían un compromiso social, una educación crítica del mundo. Por el Ministerio de Educación Pública conocimos a Luis Carlos Pérez y Gerardo Sánchez, quienes cumplieron con la coordinación por parte del Departamento de Educación de Adultos, todos ellos y ellas fueron nuestros maestros y maestras, para luego enseñar la palabra a los campesinos y las campesinas de los cantones de Nicoya y Hojancha de la provincia de Guanacaste, Costa Rica.

Por espacio de dos años viajábamos a Guanacaste; y nos trasladábamos de San José a cada una de las comunidades que nos asignaron, entre ellas: Sabana Grande, San Antonio, Mansión, San Martín, Hojancha, Nicoya centro, Matambú. En cada lugar nombraron a una persona docente universitaria, responsable de coordinar al grupo de estudiantes, en la alfabetización e inserción comunal. En mi caso, estuve en la comunidad de San Antonio, que es un distrito del cantón de Nicoya. El relacionarnos con las personas adultas, con los campesinos, y las campesinas, la comunidad, la juventud, las familias, la sociedad en general, considero que nos dejará a todos y todas llenos de sensibilidad y compromiso social, hasta el final de nuestras vidas. 


\section{¿Cómo describir cuando el campesino o la campesina se iban apropiando de la palabra, la lectura, la escritura, y su mundo?}

La cuartilla, cuaderno, guía para la alfabetización estaba diseñada con símbolos, signos socioculturales de su medio, de su entorno rural. Recuerdo muy bien el dibujo de la pala, del machete, y la emoción, de las personas adultas, que a la cuarta sesión de recibir sus clases no sólo leían la palabra pala, sino que también la escribían. Pero además comprendieron que este concepto, era su instrumento de trabajo y que lo que ellos y ellas modificaran con esa herramienta, les pertenecía; era de su propiedad y nada ni nadie se los podría arrebatar.

De esta forma, se gestaron movimientos sociales con propiedad colectiva; solicitaban mejores condiciones de vida, educación, titulación de tierras y demandas con otras comunidades. Por ejemplo en Matambú de Nicoya, hubo un grupo de jóvenes que luchó, por tener espacios en las organizaciones sociales del cantón de Nicoya, sobre todo que en esa coyuntura de los años setenta (70), emergieron múltiples organizaciones sociales y, el papel que representó el Estado costarricense ante los sectores comunales, creándose la Dirección Nacional de Desarrollo de la Comunidad (DINADECO), con el propósito de organizar, planificar, desarrollar, ejecutar y evaluar el desarrollo comunal, y, al igual que otras organizaciones sociales exigían mejores condiciones de vida. La coordinadora María Suárez y el grupo de estudiantes de la Universidad de Costa Rica, que estaban alfabetizando en la comunidad de Matambú les dieron su apoyo, tanto en lo organizativo como en lo educativo, rescatando y valorando su acervo cultural.

El tiempo fue pasando, las relaciones sociales, educativas, pedagógicas, afectivas, tanto entre el grupo de universitarios y universitarias, como el de la comunidad, se fue estrechando más y más.

Las sesiones educativas se dedicaban a la lectura, la escritura y en el desarrollo de su conciencia de clase, del ser, su quehacer y su posición social en el mundo. Esto produjo una coyuntura histórico-social, donde los movimientos sociales en Costa Rica, Centro América, América Latina y el mundo, estábamos en el proceso de luchas sociales y políticas, lo que también "invadió" a nuestro proceso de alfabetización porque trabajábamos con el método de concientización de Freire, ya que las campesinas y los campesinos aprendieron a leer palabras, haciendo la reelectura del mundo, también fue un acto político, de develar su historia de vida, tanto personal como social. 
Retomando a Freire "La verdadera lectura me compromete de inmediato con el texto que se me entrega, y al que me entrego y de cuya comprensión fundamental también me vuelvo sujeto" (1997, p. 29).

¿Pero, qué pasó? Rápidamente la Organización de los Estados Americanos (OEA) dejó de financiar el proyecto; la Vicerrectoría de Acción Social ya no pudo asumirlo económicamente y el Ministerio de Educación Pública, dejó la coordinación. Como estudiantes universitarios y universitarias con mayor compromiso que otros, continuamos por un año más, hasta 1976, pero el proyecto educativo con el tiempo desapareció.

Hoy, después de tantos años, reflexiono acerca de esta experiencia educativa, de los pedagogos y pedagogas que nos apoyaron en este reto, de los planteamientos teóricometodológicos que sustentaron esta práctica alfabetizadora, y que continúan vigentes, germinando en posiciones educativas, como la corriente pedagógica de la teoría crítica, que en asocio con las ideas y prácticas de Freire y Baró, toman fuerza y fundamentan el sentido de la educación centroamericana y latinoamericana.

Es importante en la trayectoria de la educación en Costa Rica, preguntarse acerca de la vigencia del pensamiento de ambos autores, en la transformación de la educación costarricense.

A continuación, analizaré a los autores Paulo Freire e Ignacio Martín-Baró desde el pensamiento educativo, quienes me permiten contextualizar el quehacer de la docencia universitaria en la realidad latinoamericana y centroamericana.

\section{El pensamiento educativo en Paulo Freire:}

Freire fue un educador, un ciudadano del mundo que trató de ser coherente, de hilar entre lo que decía y lo que hacía. Esta labor permanente lo transformaba cotidianamente, desde su práctica educativa, porque así como trabajaba con campesinas y campesinos de la ciudad de Pernambuco en Brasil, con los pescadores en las costas brasileñas y con las y los cooperativistas en el Caribe, con los y las inmigrantes en Europa, en Chile, en Estados Unidos, también trabajó con métodos de educación formal con la niñez y adolescentes en la secundaria. En ese recorrido por diferentes lugares de su país natal -Brasil- y otros continentes, fue estableciendo una relación dialógica con grupos sociales diferentes en actividades diversas: productivas, educativas, políticas, sociales, y fue descubriendo y autorreflexionando que existía y existe una educación domesticadora; una educación que es 
impositiva desde arriba hacia abajo; una educación verticalista, una educación como Freire la llamó una educación bancaria

...pese a la enseñanza 'bancaria', que deforma la creatividad necesaria del educando y del educador. El educador está sujeto a ella no por causa del contenido cuyo 'conocimiento' le fue transferido, sino por causa del propio proceso de aprender, hacer, como se dice en lenguaje popular; de tripas corazón y superar el autoritarismo y el error epistemológico del bancarismo. (1997, pp. 26-27).

Permanentemente en sus escritos y en su práctica socioeducativa, consideró que la función esencial de la educación, es formar personas libres y autónomas, capaces de analizar la realidad que les rodea para transformarla.

Pues, como lo menciona Freire, (1997) la persona, cuando conoce y participa sobre lo que le es inmediato, su realidad, la cambia, la modifica, al mismo tiempo que esta realidad influye y actúa sobre la persona; es decir, se relacionan dialécticamente. El sujeto asume el proceso de concientización y va descubriendo su propia condición de clase, de persona, de identidad y pasan de un estadio de "conciencia ingenua", al estadio de "conciencia realista" y junto con profesionales en la educación, cumplen el papel de facilitadores y facilitadoras de la comunicación.

Otro eje que también practiqué, cuando alfabetizamos a la población mencionada, es el manejo del contenido disciplinario, que no sólo se trataba de la educación como disciplina científica, sino que también se apoyaba en otras ciencias, principalmente en la Psicología y en la Sociología. Se trata darle el carácter de multidisciplinario e interdisciplinario al método, y así surgían y discutían tantos fenómenos alrededor de la palabra generadora o el tema generador, como es el caso de uno de los tantos que mencionó Freire en la isla de Grenada en torno de la realidad de esas personas organizadas económicamente en cooperativas agrícolas. Al respecto Freire mencionaba,

Evidentemente tendríamos que crear, situaciones hipotéticas, presentándoles elementos que tipifiquen la situación para los participantes en el seminario, se les pediría que escriban sobre ellos en un tiempo...un dibujo por ejemplo, donde se ve una típica escuela rural de la isla. (1993, p. 165).

Este método, por su vigencia y trascendencia, nos confronta con una realidad, en que profesionales, no quieren comprometerse socialmente, mucho menos a generar cambios en su vida profesional ni en la sociedad. Pero si nos apoyamos metodológicamente en las 
experiencias y en la vida de Freire, considero que nos podría guiar para seguir creyendo y practicando ese camino que no es fácil recorrerlo. Sin embargo, creo que si los que estamos involucrados en la docencia, desde una postura crítica, nos proponemos el reto de construirla y a retomar lo que Freire nos comunica en su libro Pedagogía de la Esperanza, de visualizar y autocriticar nuestra posición de educadores y educadoras, debemos considerar lo siguiente:

1. Las educadoras y los educadores deben preocuparse por investigar, buscar, y tratar de conocer, cuáles son los conocimientos, las ideas, la socialización que traen los educandos, y las personas adultas cuando están en el acto educativo formal o no formal -. El docente debe interesarse por la vida cotidiana de esta persona y de su entorno y de su condición de clase, y su cultura, que respete su identidad, que no se sienta dueño o dueña de la verdad para que le de sentido o significado a su educación. Freire explica esto como una relación dialógica, comunicativa, ya que las y los estudiantes se descubren a sí mismos y le dan sentido al significado, y toman la conciencia del mundo en donde viven.

2. En esa relación dialógica se establece la comunicación crítica, la problematización del contexto socioeconómico, cultural y político que rodea a las personas y, cuando adquiere esa conciencia crítica, real, de su quehacer cotidiano, el sujeto en el acto educativo, se transforma para asumir su libertad, para transformarse a sí mismo y con los demás, porque se necesita de las otras personas, del acto de comunicarse para intercambiar, para posesionarme del otro y la otra y comprender mi criterio con el de los demás; no para quedarme sólo con mi "saber", sino lograr establecer pedagógicamente un intercambio de saberes y de conocimientos; como decía Freire "de la lectura del mundo", ya que "todos y todas nos comunicamos en comunión".

El maestro Freire como educador, se preocupó intensamente por lo que es la enseñanza, el aprendizaje, el estudio y, todavía hoy, existen teóricos que no lograron comprender su posición crítica, su epistemología acerca de lo que es aprender, lo que es enseñar, porque Freire fue preciso en demostrar en su práctica pedagógica y, sobre todo, en el libro Pedagogía de la Autonomía que permanentemente estamos aprendiendo; no hay límites, no existen fronteras para el aprendizaje, que es importante aprender a pensar; es decir "aprender a aprender, que quien enseña aprende al enseñar y quien aprende enseña 
al aprender, quien enseña, enseña alguna cosa a alguien". (1997, p. 25). Freire con estos principios, evidencia que a través del aprendizaje social, históricamente los hombres y las mujeres han construido métodos y estilos de enseñanza: "todos nos educamos en comunidad", en proyectos comunes, con autonomía.

Freire, desde su pensamiento educativo, enuncia que el acto de educar es un proyecto inacabado con capacidad de dolor, asombro, emoción, compromiso para y con el ser humano y, que además, tiene incorporado una posición ideológica, de clase que le hace "ver" su realidad de acuerdo con su condición de clase. Desde la educación liberadora de ese ser social, lo entiende en la construcción de involucramiento de todo el cuerpo: en la esperanza, en la curiosidad, la alegría, los gustos, los afectos y también los sufrimientos, porque si el conocimiento resulta significativo y atractivo, se logra un conocimiento en que el sujeto es partícipe y copartícipe del conocimiento en construcción, de la opción por la emancipación. Él considera que el conocimiento no es un proceso de transmisión de información, sino que la persona que está en condición de educando, tiene su protagonismo; se convierte en sujeto de su propio conocimiento, y lo produce por medio de la investigación, en tanto que la generación de ese conocimiento, a través de la investigación, son indisolubles. Es importante destacar que en Freire surge la posibilidad de darle valor a los saberes científicos, en esa condición de diálogo como método para comunicarse y lo mediatiza en el conocimiento de lo que, ya sabe por ejemplo el obrero, o en el caso del estudiantado que se encuentra en la educación formal, se establece esa creación y recreación del conocimiento, ya sea en el aula o en los círculos de cultura, a los que Freire tan, vehemente, describe en sus obras.( Freire, 1997).

Pero ¿cuál es la responsabilidad del docente o del facilitador o de la facilitadora ? Estos funcionarios, deben preocuparse y comprometerse para que el y la estudiante, el sujeto que está en el proceso educativo, también se comprometa, comprenda y sea responsable de su mismo proceso y que realmente cumplan su papel de orientación para que comprendan el contexto, el mundo y la situación particular en donde se desenvuelven para que tomen conciencia de la vida en la que están conviviendo y relacionándose, para Freire es una "tarea política de alta importancia pedagógica" (1994, p. 129). Por lo tanto, hay que asumir una posición crítica, vigilante, indagadora, contestaria, y es necesario que los profesionales en educación se flexibilicen en los espacios de la cultura popular, en la educación comunitaria y que logren, junto con las personas involucradas, a crear y recrear un conocimiento nuevo, y que no se autovaloren como únicos o únicas para conocer la verdad. 
Paulo Freire, demuestra cómo se rompe con el sistema educativo tradicional y llama a la utopía sobre la vocación universal de la educación y, con su propia práctica demuestra que al liberarse a sí mismo, se libera a la sociedad y se emancipan obreras, obreros, estudiantes, educadores y educadoras, amas de casa, campesinos y campesinas, y se logra construir una sociedad justa, sin opresión, y que sus integrantes dejen de estar oprimidos, para que en la emancipación, invada a todos los dominios de la vida en sociedad. Freire menciona "El papel del educador o de la educadora progresista que no puede ni debe omitirse, al proponer su lectura del mundo, es señalar que existen otras lecturas del mundo diferentes de la suya y hasta son antagónicas en ciertas ocasiones" (1993, p. 107).

\section{¿Cuáles implicaciones educativas universitarias, se darían desde la postura del pensamiento educativo de Freire?}

El momento histórico actual de las universidades estatales, en contextos de globalización y educación neoliberal, demanda de ellas un compromiso sociopolítico que garantice, no sólo la legitimación de la educación pública superior, sino también su excelencia académica e inserción en la sociedad costarricense.

Enfrentar y asumir el reto, necesita de un esfuerzo conjunto, que apoyado en la docencia, la investigación y la acción social, desde la integración teórica y práctica, permanecen en todos los niveles del quehacer universitario.

Si situamos a la universidad pública en el contexto de la sociedad costarricense y en particular, en la Universidad de Costa Rica (UCR), es posible develar y analizar desde su interior, si la pedagogía liberadora es un escenario de la universidad.

¿Por qué la Universidad de Costa Rica? Quizás sea porque me formé como profesional en esta institución y porque he laborado durante varios años en ella y es la universidad, que en mi generación, nos formó con principios, valores y una filosofía comprometida con los desposeídos y desposeídas, para que cuando fuéramos profesionales, devolviéramos a la sociedad, lo que en su momento, ella nos brindó y que lográramos que la juventud estudie en tan magna institución.

De acuerdo con sus principios y normas estipulados en el Estatuto Orgánico artículo 3, la Universidad de Costa Rica establece que el propósito de la universidad es "obtener las transformaciones que la sociedad necesita para el logro del bien común, mediante una política dirigida a la consecución de una verdadera justicia social, del desarrollo integral, la libertad plena y la total independencia de nuestro pueblo". 


\section{Pero, ¿qué está sucediendo en el contexto universitario desde la pedagogía liberadora?}

La docencia universitaria cumple una de las dimensiones prioritarias en el desarrollo universitario; constituye en sí misma un reto, independiente de la disciplina en que se trabaje.

La labor de la y el docente universitarios, es una tarea compleja y comprometida en un proceso educativo; por ello se circunscribe en la necesidad de formar profesionales que trabajen como docentes en la universidad y de cultivarse en el campo de la pedagogía universitaria para que orienten su práctica docente.

Si la docencia se sustenta en una teoría crítica, entonces dicha teoría orientará necesariamente los procesos de la enseñanza-aprendizaje en los que participan sujetos protagonistas: docentes y estudiantes para generar conocimientos como el objeto de estudio.

Pero lo común, es cuando el trabajo del profesorado universitario, se focaliza en el desarrollo del curso o de los cursos que le asignen en su escuela, departamento o facultad y se aísla de su entorno para practicar una docencia de transmisión de contenidos.

Sin embargo, si el profesional asume una docencia en la disciplina en que se formó; pero también responde a las demandas sociopolíticas, tanto en el campo de los conocimientos, como en los valores y en las actitudes, participaría en los procesos de formación y de desarrollo pleno de la persona.

Así se desarrollaría una práctica docente que se sustenta en un pensamiento crítico, y se orienta a la formación de estudiantes creativos y críticos que reflexionen sobre su quehacer de estudiantes y futuros profesionales, con actitud crítica hacia la investigación, la acción social y el compromiso con los problemas de la sociedad.

Freire postula en su obra Pedagogía de la Autonomía, las siguientes características de la tarea docente: enseñar exige un rigor metódico, con el propósito de estimular la capacidad crítica, la curiosidad y la insumisión del educando; demanda la investigación como un proceso inherente a los de enseñar y aprender.

En Freire enseñar exige respeto a los saberes de las y los educandos, considera sus experiencias y saberes previos; exige también crítica, supera la curiosidad ingenua por la curiosidad crítica "...implica el compromiso de la educadora y el educador con la conciencia crítica del educando cuya promoción desde la ingenuidad no se hace automáticamente". (1997, p. 31). 
Enseñar demanda ética (por el sentido de la formación), y estética (gusto, belleza); la enseñanza no debe ser desagradable y, menos un aburrimiento. Exige dar ejemplo, enseñar con el testimonio, en la teoría y en la práctica. Exige riesgo, propiciar lo nuevo y rechazar cualquier forma de discriminación y conlleva el pensamiento crítico de la docencia y asumir y respetar la identidad cultural de todos los y las participantes. Freire al respecto expresa esta actividad tácticamente: la comunidad educativa.

Con estos principios y aprehendiéndolos en nuestra práctica docente, es necesario y prioritario reflexionarlos en el contexto de la pedagogía universitaria.

La pedagogía universitaria responde a la reflexión de la educación superior y a la educación universitaria de manera específica. La docencia universitaria está comprometida con la preparación de profesionales que reúnan una sólida formación en el campo de la disciplina y que tengan un compromiso humanista. Esto implicaría la implantación de conocimientos con compromiso y posición democrática, progresista, sin distinciones de clase social frente la realidad social, así como valores y actitudes ante el ser social.

De esta manera se plantea que la docencia universitaria:

- Está vinculada con la investigación y la acción social, como expresiones subyacentes de la actividad académica que se realimentan y enriquecen mutuamente.

- Requiere de un enfoque integrado, desde lo multidisciplinario e interdisciplinario, desde la disciplina relacionarla con otras disciplinas, para una comprensión y reflexión del fenómeno educativo en estudio.

- Que promueva la resignificación de los conceptos y símbolos, y asuma la posición de autocrítica permanente de su quehacer y de su hacer, para tomar un compromiso personal y social.

- Asuma la pedagogía de la liberación para que las y los estudiantes y las y los docentes nos organicemos en grupos sociales contestatarios y no desde lo individual: que se intercambien momentos de esperanza - de sueños - de utopía - de cambios sociales y políticos.

- Se realiza en una institución que tiene un compromiso científico, social y político (la UCR lo define en el Estatuto Orgánico). Por tanto, esta docencia debería trascender el trabajo de aula y de un curso particular. Es cierto que la Acción Social cumple con este principio, pero, hay que profundizar dicho compromiso en la realidad socioeconómica del país y en la misma Universidad. 
La reflexión de la práctica docente es importante en el desarrollo de la pedagogía universitaria, al permitir su interpretación y teorización. El estudio de los fenómenos educativos y sociales, ubicados en el contexto histórico-social y político y en las expectativas que se tengan, remite a los planteamientos teóricos y a reformular nuevas opciones nuevamente. La confrontación entre la teoría y la propia práctica docente y su superación constante, se considera una estrategia de formación y capacitación pedagógica comprometida.

\section{El pensamiento educativo en Ignacio Martín-Baró:}

La función social de la universidad de acuerdo con Tünnermann (1997, p. 28), consiste esencialmente en que a ella acude la sociedad en busca de la orientación, de conocimientos e inspiración. En cumplimiento de la misma, la universidad debe participar en una forma principal, en los esfuerzos dirigidos a promover los cambios estructurales que la sociedad requiere para que sea más justa.

Este principio es clave y es fundamental para el análisis que nos entrega Martín-Baró y además rige en las universidades públicas, a pesar de las limitaciones presupuestarias que cada año o cada período nuevo de gobierno, ya que quieren ahogar y, si es posible, anular del presupuesto de la República, el porcentaje asignado en el Fondo de la educación superior (FESS) para el financiamiento de nuestras universidades estatales de Costa Rica.

El aporte significativo que Baró nos brinda, es coincidente con las personas que nos identificamos con los desafíos que las universidades públicas pueden aportar para el presente y el futuro, a través del Siglo XXI, porque entre sus principios está el permitir la integración de la docencia, con la investigación, la acción social o la extensión. Es dar oportunidad a la población en general para poder continuar con su educación, y tal como nuestro educador y ex rector de la Universidad de Costa Rica, Carlos Monge Alfaro lo expresó: "el proceso mediante el cual el ser humano alcanza su libertad". (1965, p. 65).

Este principio está presente cuando Escotet citado por Tünnerman, expone la trascendencia que tiene la educación, si la valoramos "con un carácter integrador, como un proceso innovador, que deben partir de un contexto social específico, al servicio de grupos sociales determinados", (1997, p. 82).

Sin embargo, hay que redefinir como en la sociedad actual, los excluidos y las excluidas del sistema universitario se acrecientan por no tener el acceso económico suficiente para sobrevivir en un ambiente universitario discriminatorio. Para estudiantes que 
ingresan por vez primera, se reproduce el clasismo, por ejemplo desde si es de un colegio privado y/o público; por la procedencia geográfica, si es rural o urbano, debido a su estatus familiar y social, hasta la misma selección de la carrera profesional, ya lleva un signo clasista, si además es inteligente o mediocre.

Martín-Baró nos invita a repensar en nuestras universidades estatales, tomando como punto de partida, las contradicciones de la estructura social y económica de nuestros pueblos centroamericanos; pero también quienes continuamos en esta lucha, debemos asumir el reto, el desafío del papel de asombro, de imaginación y de retos que cotidianamente en la universidad pública, debemos reflexionar y comprometernos con los que han sido desposeídos de los privilegios académicos; pero también con los excluidos de integrarse a un sistema educativo discriminatorio y que Baró lo señala desde la pedagogía, al defender la universidad como una conquista social y no para reproducir y perpetuar la ideología de la clase dominante y de los intereses de ciertos sectores sociales que quieren imponer su visión del mundo para toda la comunidad universitaria, a través de las relaciones de poder que se imponen.

Martín-Baró luchó por la emancipación del pueblo salvadoreño y centroamericano, desde el ámbito universitario, en el protagonismo que debe asumir la universidad en la lucha política, en la cual se expresan los antagonismos surgidos de las clases sociales, del tipo de docencia y pedagogía universitaria clasista, de las disciplinas científicas universitarias afines a los intereses de una élite, a la formación de los y las profesionales(no ligados a los intereses del pueblo, a una universidad donde se privilegia el método técnico, pragmático y no se estimula y desarrolla la creatividad, no se practica un currículum flexible, humanista. Además, Martín-Baró descarta una universidad que impone una docencia tradicional, llena de mitos, y que en sus aulas se reproduce antagónicamente la división de las clases sociales: en la clase dominante y la dominada, en la clase oprimida y la opresora, y que en sus propias palabras dijo: "una docencia será alienada en la medida en que la conducta de profesor y alumno esté determinada por mecanismos ajenos a ellos" (1979, p. 46).

Así, se impone contra una universidad donde convergen las metodologías, las técnicas, los textos, "importados" desde otras fronteras, ni valora los textos y su consulta como el saber permanente que ya viene organizado, programado y hasta como ser evaluado desde países extraños a nuestra cultura, a nuestro pensamiento, y a nuestra realidad.

Esta visión se opone a una universidad donde los docentes universitarios transmiten contenidos descontextualizados y que las y los estudiantes deben memorizar y repetir, tal y 
como el profesor o profesora lo exige, para lograr ser estudiantes exitosos e incorporarse profesionalmente en un mercado altamente competitivo.

Martin-Baró logra desmenuzar esta realidad de la universidad salvadoreña en particular, y de la universidad centroamericana, en lo regional, desde una posición contestataria, que tiene por tarea, descubrir por qué la lucha continúa.

Pero además, desde la crítica de la universidad, hace también la crítica de la sociedad, de las formas individuales y sociales de la conciencia, y como se practican desde la educación, la ciencia, la economía, lo político, e implica también lo ideológico. Porque, para este personaje el significado de la universidad elitista es ir "permitiendo el ingreso a nuestras aulas, prácticas de aprendizajes foráneas, que resultan ser alienadoras". (Citado por Rolando Quesada Sancho, 2003).

Para Ignacio Martín Baró (1979), al reclamar el papel que debe asumir la UNIVERSIDAD para ponerla al servicio del pueblo, aboga por la democratización universitaria, por una relación entre la teoría y la práctica, lo importante es la lucha práctica de la liberación del pueblo, y de todos y todas los que conformamos la comunidad universitaria, para que al relacionarse la teoría y la práctica, se logre lo que Martín-Baró tan lúcidamente manifiesta que "...democratizar la universidad quiere decir ponerla al servicio integral del pueblo, hacerla vibrar con sus necesidades y problemas, ponerla a soñar y a trabajar en la resolución de su marginación histórica y en la transformación de sus esquemas sociales" (1979, p. 80$)$.

Martín-Baró así dibuja una universidad comprometida en una sociedad transformadora, que logre conducirse hacia una relación de tipo dialogal para que pueda destruir la relación vertical y dominante y que se construya en un trabajo de cooperación, que se convierta en una necesidad histórica, se superen dialécticamente las relaciones sociales, académicas, históricas, culturales y educativas dominante y, una vez superadas dichas contradicciones, que contextualicen en un ambiente democrático y abiertamente crítico. Su corriente de pensamiento comprometida con lo humano, con la realidad salvadoreña y regional, como el aspecto económico de la pobreza, se hace presente en la persona, en la carencia de alimentos y techo, de necesidades básicas como la educación y la salud, en la explotación del trabajo y en el desempleo permanente, en la falta de respeto a la dignidad humana, en el sufrimiento cotidiano, en lo racial, lo cultural y lo religioso.

Según Baró, al estudiantado universitario hay que brindarle la posibilidad y responsabilidad de participar en la lucha por la justicia social y por la transformación social, 
cuando expresa: "el estudiante universitario debe constituirse en el despertador de su ciencia al servicio de la causa histórica de un pueblo" (1979, p. 81).

A Martín-Baró, lamentablemente por la lucha de sus principios, por la lucha de una universidad integrada en y con el pueblo, por la lucha de evidenciar las contradicciones y la explotación que surgían diariamente en la sociedad y en las instituciones sociales salvadoreñas y centroamericanas, lo asesinaron vilmente, pero no lograron destruir su espíritu, sus ideas, ni su pensamiento crítico, porque a pesar de que sus obras escritas ya superan los treinta (30) años, aún en los inicios del Siglo XXI, su pensamiento continúa estando actualizado y vigente.

\section{¿Cuáles implicaciones en la educación general, se darían desde la postura del pensamiento de Martín-Baró?}

Según este autor $y$, desde la pedagogía son relevantes la relación y sus consecuencias que pueden suscitarse en la educación formal. Analicemos el por qué:

$\diamond$ Para Baró, la transformación de la sociedad sería posible, si en las instituciones educativas, se brindara una formación política, comprometida con los sectores sociales desfavorecidos y desposeídos por los que tienen el poder económico y político. Si la formación educativa fuera una búsqueda permanente de valores autónomos, propios de cada región o de cada país.

$\diamond$ En el análisis de la situación educativa, Baró contempla la necesidad de incorporar y legitimar, de parte de las autoridades gubernamentales, un currículum flexible, dinámico, que logre estar incorporando el movimiento y las necesidades y las características de una sociedad que está cambiando permanentemente.

Se debe desarrollar un currículum que no se centre sólo en el conocimiento, lo técnico, o lo instrumental, si no que en ese continium del ejercicio educativo, esté abierto a la transformación de los principios que sustentan ideológicamente la cultura educativa. Es necesario implantar un currículum que sirva de enlace entre la teoría y la práctica, para que la comunidad educativa inmersa en esa realidad, sienta que los contenidos, la metodología, la evaluación y lo que concierne a esa práctica educativa, esté actualizada y llena de desafíos para la educación.

Este currículum debe estar permeado por la ideología que se identifique con los intereses de clase de una mayoría, no que suceda lo contrario, que sólo responde a un sector minoritario para satisfacer sus proyectos individuales de clase poseedora y que logra 
conformar cuadros de profesionales vacíos de una identidad y sentido de pertenencia, ajenos a la realidad como puede ser la realidad de cada país centroamericano.

Asimismo el currículum debe lograr en su planificación incorporar las voces de los desposeídos, de los que no tienen participación y toma de decisiones, como plantea Baró es fundamentar que tenga sentido de comunidad o de sociedad.

$\diamond$ Otro aspecto importante por considerar en las implicaciones, incorporar y legitimar políticamente la relación entre la docencia, la investigación, y la acción social.

Al menos en Costa Rica este "privilegio" se encuentra sólo en las universidades públicas, la investigación que se genera, promueve el conocimiento para nutrir, alimentar a la docencia y ese conocimiento se "devuelve" a la sociedad, a través de la Extensión o Acción Social universitaria.

Sin embargo en los otros sectores educativos, como es la educación preescolar, la educación primaria y la secundaria no se contempla, mucho menos se practica. Anteriormente argumenté que es un privilegio y así es, porque si la investigación científica fuera el motor del quehacer del proceso de enseñanza-aprendizaje en esta región centroamericana, o más específico en nuestro país, obligaría a toda la estructura educativa y política, a las relaciones de poder que se tejen permanentemente, a tomar una posición de vigilantes o de temor, porque considerando los principios de la pedagogía crítica como pensamiento político, la investigación científica develaría en sus resultados y constante práctica investigativa, una realidad que no le conviene a los que detentan el poder económico.

De esta forma, se lograría despertar en las y los estudiantes y docentes, en fin, en la comunidad educativa, una actitud de asombro; una capacidad de profundizar en lo que se encuentra superficialmente, generaría conocimiento y compromiso social e individual; formaría personas contestarias, críticas ante un sistema educativo que practica una pedagogía vertical. $\mathrm{Y}$ desde esta integración entre la docencia, la investigación y la acción social, obligaría a practicar una Pedagogía Horizontal, como la llamó Baró, que demande un respeto hacia la identidad que requiera una pedagogía sin discriminación y con privilegios sólo para una minoría. Formaría una sociedad diferente con seres sociales críticos, emancipados y comprometidos por una transformación, desde lo educativo hacia el quehacer del individuo y lo colectivo. Comprometidos con el pueblo, las y los estudiantes y profesionales tendrían capacidad no de obedecer, sino de asumir posiciones críticas, resolutivas y no satisfacer solamente sus necesidades individuales, sino se lograría una 
capacidad de solidaridad, de entendimiento; en fin seríamos otra sociedad ajena a lo que estamos practicando actualmente.

$\diamond \mathrm{Si}$ el sistema educativo, en su estructura político-administrativa y técnica (relaciones de poder y de autoridad) lograra cristalizar el compromiso ligado al pueblo a través de ese engranaje de reformas, de artículos, de decretos, de políticas, y asumiera, por ejemplo la capacitación de docentes, para que incorporaran a través de su práctica educativa, el concepto que la capacitación docente no es sólo instrumental, o de entrenamiento, o la necesidad de mejorar habilidades y destrezas. Si la capacitación fuera un proceso político permanente entre las personas que se relacionan en la comunidad educativo-social, otra sería la dinámica de nuestra sociedad educativa.

Si con la capacidad de autoridad que tienen los maestros y maestras, los y las profesores en secundaria y universitaria, al menos en la educación costarricense y si todos y todas estos profesionales asumieran - y por supuesto que me incorporo - un papel de criticidad, de formación de valores propios, con nuestra realidad para desarrollar y practicar una cultura autóctona, de trabajar en comunidad y que a nuestros estudiantes les lográramos proyectar estos principios, ¿qué sociedad sería en estos momentos?

Pero en el ejercicio de la docencia, como Baró (1979) lo denunció, por qué no se practica una docencia nueva, una docencia atractiva, creativa que logre motivar a docentes y estudiantes, y no sólo consista en repetición de contenidos, en usar la memoria y no la creatividad, en la enseñanza de métodos tradicionales y en algunos casos ya desactualizados, ¿por qué los y las docentes permanecen en un letargo mental de repetición de programas? ¿por qué no desafían a las estructuras vigentes ?

Baró formuló una alternativa crítica a tomar una postura de docentes críticos o una docencia crítica, comprometida con la sociedad. Como lo mencioné en la introducción, desde la estudiante soñadora y ahora como profesional soñadora, doy testimonio de la teoría y la práctica, de lo indivisible entre ellos, no existen fronteras que logren enmarcar estos principios cuando realmente se compromete con el ejercicio de la teoría y la práctica educativa, y a pesar de los obstáculos en el ejercicio docente, trato de crear espacios para construir y apropiarme del método de la palabra, de lo humano, que más que brindar conocimientos puros, es educar para la formación de un pensamiento político-pedagógico que desafíe, que permita practicar los conocimientos y que luego sistematicen teóricamente la práctica enriqueciendo a la teoría. 
Para Freire (1997, p. 108),

el educador y la educadora críticos no pueden pensar que, a partir del curso que coordinan o del seminario que dirigen, pueden transformar el país. Pero pueden demostrar que es posible cambiar. Y esto refuerza en él o ella la importancia de su tarea político-pedagógica.

Traigo estas memorias nuevamente conmigo, porque han estado en mi práctica profesional y, como socióloga y educadora, vivencié como el ser humano cuando se apropia de la palabra, se libera, y no deja que lo "domestiquen". Conocí físicamente a Paulo Freire en mi época de juventud, de sueños e ilusiones y, ahora que soy persona adulta, docente universitaria, que soy, sigo, seguiré luchando por la justicia social, para que las mujeres y los hombres nos miremos y trabajemos por la equidad, por una educación democrática, porque para Freire y Martín-Baró, su método, su práctica social, educativa y política, no quedaron en el vacío. Aún existimos seres sociales que creemos en las utopías y que hay que construirlas, para que otras personas en espacios diferentes continúen luchando y enriqueciendo dichos aspectos.

\section{Conclusiones}

Es de mi interés, como profesional seguidora del pensamiento educativo latinoamericano, destacado en este espacio por dos pedagogos latinoamericanos: Paulo Freire e Ignacio Martín-Baró, analizar en sus posiciones epistemológicas puntos de convergencia como los siguientes:

$\checkmark$ Las relaciones sociales, económicas y políticas, ponen de relieve las contradicciones educativas y demuestran científicamente que la sociedad puede transformarse si existiera desde el componente político-educativo, un compromiso y voluntad para la transformación de estructuras equitativas para las personas que convivimos en un momento y un espacio histórico determinados.

$\checkmark$ Dichas contradicciones pueden superarse y además, desde el pueblo pueden transformarse históricamente. 
$\checkmark$ Desde el contenido real de las formas educativas, culturales, económicas, se desarrolla la educación política. Ambos pedagogos hacen notar que si las cosas continúan de acuerdo con la voluntad de los que tienen el poder económico y político, la educación sigue siendo el instrumento ideológico de dominación, que sirve para reproducir y perpetuar sus propios intereses de clase social dominante.

$\checkmark$ La educadora y el educador comprometidos son dinámicos, democráticos, progresistas, se encuentran en la búsqueda permanente de analizar la práctica y, si es posible de percibir en la práctica, una teoría poco percibida pero poco asumida como proceso de transformación. Si se asume la posición crítica para comprender los problemas cotidianos y los problemas estructurales, ya que en otro momento, sólo los "especialistas" se adueñaban de la verdad, es despertar a la curiosidad y al asombro.

$\checkmark$ Los procesos de reflexión teórico-crítico en ambos pedagogos, se construyen a partir de cuatro categorías fundamentales: la pobreza, la realidad, la liberación y la utopía. No se interpreta a la realidad; lo que realmente les desafió, fue transformarla.

\section{Referencias}

Bernstein, B. y otros. (2000). Ensayos de Pedagogía Crítica. España: Editorial Popular.

Castells, M. y otros. (1994). Nuevas perspectivas críticas en educación. Barcelona: Ediciones Paidós Educador.

Freire, P. (1997). Pedagogía de la autonomía, saberes necesarios para la práctica educativa. México: Editorial Siglo Veintiuno editores, S.A.

. (1994). Educación y participación comunitaria. En Nuevas perspectivas críticas en educación. Barcelona: Ediciones Paidós Educador.

. (1993). Pedagogía de la esperanza, un reencuentro con la pedagogía del Oprimido. México: Siglo veintiuno editores. S.A.

Giroux, H. (1990). Los profesores como intelectuales. Hacia una pedagogía crítica del aprendizaje. Ediciones Paidós: Barcelona. 
crítica. México: Editores Siglo XXI.

Martín-Baró, I. (1979). Haciendo la universidad. Guatemala: Cuadernos Universitarios FUPAC.

Monge, A. C. (1965). Carlos Monge Alfaro: La filosofía de la educación y la universidad. Revista de Filosofía. (17), pp. 65-75.

Tünnermann, C. (1997). Aprender para el futuro. La educación frente al cambio. San José, Costa Rica: Educa-CSUCA. 